\title{
KRISTUS BANGKIT MENEBUS DUNIA Refleksi Ekologis Atas Paska
}

\author{
Largus Nadeak*
}

\begin{abstract}
Abstrak
Perayaan Paska menghadirkan kenyataan kebangkitan Yesus Kristus Penebus semua ciptaan. Allah Pencipta berinkarnasi, hadir dan tinggal bersama ciptaanNya dengan kelahiran dan kehadiran Yesus Kristus di bumi. Allah yang hadir bersama ciptaan nyata menderita, mati dan terutama bangkit untuk menebus semua ciptaan, bukan hanya manusia tetapi semua ciptaan yang hidup dan tidak hidup, yang kelihatan dan tak kelihatan. Manusia penghayat iman kebangkitan Kristus yang ditebus, mengaktualisasikan penebusan yang dialami dengan memelihara ciptaan agar pengalaman kebangkitan ciptaan menjadi nyata. Sikap dan tindakan paska direalisasikan secara personal dan bersama di tempat masing-masing, sehingga bumi menjadi tempat tinggal yang harmonis untuk Allah Pencipta dan ciptaan-Nya termasuk manusia dan ciptaan lain.
\end{abstract}

Kata-kata kunci: Kristus, Paska, dunia, ciptaan, ekologis, bangkit, kekal, tindakan.

\section{Pendahuluan}

Perayaan Paska menghadirkan peristiwa kebangkitan Kristus. Peristiwa iman ini membawa penebusan bukan hanya pada manusia saja tetapi juga pada semua ciptaan Allah. Peristiwa penebusan ini menjelaskan bahwa Allah tetap setia bersama ciptaan, agar semua ciptaan tersebut hidup sebagaimana direncanakan-Nya yaitu damai, harmonis dan bahagia di bumi. Kecenderungan manusia untuk "meninggalkan bumi" dengan menjadikan bumi dan isinya sebagai objek kepentingan dan kegunaan bagi manusia, harus berubah menjadi kebiasaan yang menghormati Pencipta dan saling menghormati sebagai sesama ciptaan. Bumi adalah rumah Allah Pencipta bersama dengan ciptaan (manusia dan lainnya).

Dengan wafat dan kebangkitan-Nya Kristus membarui seluruh ciptaan. Dalam dunia baru yang ditebus Kristus, keselarasan dan perdamaian antara manusia, dunia dan Allah direalisasikan. Dengan perbuatan nyata secara personal dan bersama, orang beriman Paska, 
dipanggil untuk mengusahakan realisasi keselarasan dan kedamaian semua ciptaan di bumi secara lestari. ${ }^{1}$

\section{Kristus yang Bangkit dalam Pemahaman dan Penghayatan}

\section{Konsep umum}

Peristiwa Paska adalah peristiwa kebangkitan Kristus dalam hidup abadi. Orang yang percaya pada-Nya memperoleh hidup kekal dan lestari. Peristiwa Paska juga menegaskan bahwa Allah setia bersama ciptaan-Nya, yaitu manusia bersama dengan ciptaan lain.

"The redeeming death, like the resurrection, is a part of God's plan. It is fulfilled according to the scriptures. This statement is absolutely necessary, even more than in the case of the resurrection, for it is not simply a question of saying that his death occured 'according to the definite plan and foreknowledge of God' (Acts 2, 23; cf. 3, 18; 4, 28; $13,29)$. Its redeeming nature was prophesied in the poem of the Servant of God (Is 53, 4-5, 6-8, 11-12). It is here that the believer finds the key to a profound understanding of the death and resurrection of the Christ."2

Misteri peristiwa Paska tidak bisa direduksi hanya pada peristiwa yang sudah berlalu saja, bukan juga pada hanya peristiwa saat ini, tetapi merupakan peristiwa berlanjut dan kekal bahwa Allah menjadikan dunia baru dengan menebusnya. ${ }^{3}$

"The paschal mystery is in every sense the fulness of the Incarnation." ${ }^{4}$ Dengan peristiwa Paska yang berhubungan erat dengan inkarnasi, karya dan kematian Kristus, seluruh ciptaan, baik umat manusia, maupun segala binatang, tumbuhan, langit, lautan, daratan, dan seluruh alam semesta termasuk yang kelihatan dan yang tidak

${ }^{1}$ Widyahadi Seputra, dkk. (ed.), Kajian Lingkungan Hidup, Tinjauan dari Perspektif Pastoral Sosial, Jakarta, Sekretariat Komisi PSE/APP KAJ dan Komisi PSE-KWI, 2010, hlm. 110.

2 Xavier Léon-Dufour, Resurrection and the Message of Easter, New York, Geoffrey Chapman 1974, hlm. 11.

${ }^{3}$ Xavier Léon-Dufour, Resurrection..., hlm. 12.

4 F.X. Durrwell, "Resurrection of Christ" dalam New Chatolic Encyclopedia, Volume XII, Washinton, The Catholic University of America 1967, hlm. 414. 
kelihatan disucikan sehingga semuanya menemukan makna dan tempat yang baru (Kol. 1, 15-20). ${ }^{5}$

Doa Syukur Agung dalam perayaan Ekaristi yang dirayakan pada hari Minggu (hari kebangkitan) dan juga pada hari dan kesempatan lain, secara eksplisit berisi, "Sungguh kuduslah Engkau, ya Bapa. Segala ciptaan memuji Engkau. Sebab, dengan perantaraan PutraMu Tuhan kami Yesus Kristus, dan dengan daya kekuatan Roh Kudus, Engkau menghidupkan dan menguduskan segala sesuatu"6 Perayaan ritual Ekaristi berpengaruh dalam hidup sehari-hari kalau orang beriman peduli terhadap lingkungan, dan menjaga seluruh ciptaan. ${ }^{7}$

Dengan inkarnasi dan kebangkitan Kristus, Allah tidak membatasi diri-Nya menjadi transenden tetapi hadir dan imanen di dunia. Hanya dalam dan melalui Kristus yang hadir di bumi, seluruh ciptaan dapat menjadi ciptaan baru, sebagaimana manusia adalah ciptaan baru dalam Kristus $\left(2\right.$ Kor 5, 17). ${ }^{8}$

\section{Penghayatan Fransiskus}

Fransiskus memberi perhatian banyak pada derita dan salib Kristus. Dia mengajak orang beriman untuk membina relasi intim dengan Allah yang disalibkan, agar dengan mati bersama Kristus orang beriman bangkit bersama Dia ke dalam hidup baru. Menurut Bonaventura, "Bagi para fransiskan awal, salib adalah ungkapan yang paling jelas dari cinta Allah kepada kita." 9 tersalib.

St. Fransiskus berusaha meniru derita dan kematian Kristus yang

5 Widyahadi Seputra, dkk. (ed.), Kajian Lingkungan Hidup..., hlm. 62; Paus Fransiskus. Ensiklik Laudato Si', tentang Perawatan Rumah Kita Bersama, Jakarta, Obor, 2015, no 100; F.X. Durrwell, "Resurrection...", hlm. 419.

${ }^{6}$ Doa Syukur Agung III dalam Konferensi Wali Gereja Indonesia, Tata Perayaan Ekaristi, Yogyakarta, Kanisius 2005, hlm. 135.

7 Paus Fransiskus. Ensiklik Laudato Si'..., no. 236; F.X. Durrwell, "Resurrection...", hlm 417.

8 Pendapat Martin Luther dalam Larry, Rasmussen, Komunitas Bumi, Etika Bumi, Merawat Bumi demi Kehidupan yang Berkelanjutan bagi Segenap Ciptaan, Jakarta, BPK Gunung Mulia, 2010, hlm. 511-512; Widyahadi Seputra, dkk. (ed.), Kajian Lingkungan Hidup..., hlm. 62.

9 Pendapat Bonaventura dalam Ilia Delio, Doa Fransiskan... hlm. 27. 
"He was made like Christ in his resurrection, and this in two sense. First in a literal sense, because he mortifies his flesh to such an extent that it turned black; then at his death, his flesh became so radiant and shining as though he had been raised from dead. Second, he was made like the risen Christ because he rose from the death of $\sin$ by the grace of his Creator, as the Lord rose from the death of the body by His divine power. The Lord granted Saint Francis the remission of all his sins... The forgiveness of sins is a kind of resurrection from the dead because sinners are as it were dead, without feeling and movement" 10

St. Fransiskus menghubungkan makna kebangkitan sebagai pengampunan dosa. Dia berusaha lebih dahulu menghakimi dirinya agar dia tidak dihakimi Allah. Karena dia berusaha membersihkan dosanya maka dia tidak takut mati. Dia mengajak manusia agar betobat terus menerus, dan agar berjaga dalam kebaikan. Dalam usaha menghayati pertobatan, Fransiskus membandingkan hidup manusia bagaikan bunga yang segar waktu pagi tetapi kalau tidak dipelihara dengan baik, bisa saja sudah menjadi seperti jerami di sore hari.11 Sehubungan dengan ide dan usaha hidup lestari segala ciptaan, Fransiskus mengatakan pada para saudaranya semua tumbuhan termasuk semak diberi kesempatan untuk bertumbuh. Semua ciptaan bernilai dan berharga dalam dirinya dalam tata keharmonisan bersama, maka nilai ciptaan bukan ditentukan oleh kegunaan sesaat bagi manusia.

Dengan mendalami keyakinan St. Fransiskus, St. Bonaventura (pengikut setia St. Fransiskus) mengatakan,

"Redemption is integral; the completion of the world. However, such redemption is cosmic. In the cross, God reaches down to what is furthest from him and reconciles all things in his love... The salvation of the cosmos the process by which God brings to completion the world which God creates is mediated through the salvation of humanity. However, salvation is larger than humanity." 12

${ }^{10}$ Regis J. Amstrong, et al. (ed.), Francis of Assisi, Early Documents, vol. II, New City Press, New York, 2000, hlm. 816.

${ }^{11}$ Regis J. Amstrong, et al. (ed.), Francis of Assisi..., hlm. 816-817.

12 Pendapat St. Bonaventura dalam Ilia Delio, Revisting the Franciscan Doctrine of Christ, cdn.theologicalstudies.net, hlm. 17. 
Dalam perpesktif ini, penebusan merupakan tindak lanjut penciptaan, juga merupakan perbaikan kerusakan dalam kemanusiaan dan alam ciptaan sehingga bumi dan isinya tetap berorientasi pada realitas ciptaan baru dalam cinta Allah yang kreatif. ${ }^{13}$ Ditambahkannya, "Melalui kebangkitan-Nya, Kristus berbagi hidup dengan seluruh ciptaan... Kristus memiliki sesuatu yang sama dengan ciptaan. Dengan batu Dia berbagi keberadaan (eksistensi); dengan Dia berbagi hidup; dengan hewan dia berbagi perasaan, dan dengan para malaikat Dia berbagi kecerdasan."14

\section{Allah Menebus Segala Sesuatu}

Allah Bapa adalah pencipta dan sumber segala sesuatu. Dengan mata iman tampak jelas bahwa Allah hadir dalam semua ciptaan-Nya. Penciptaan Allah Bapa berjalan bersama dengan karya penebusan-Nya dalam Kristus yang dengan wafat dan kebangkitan-Nya "mendamaikan segala di surga dan di bumi" dengan Allah. (Kol 1, 20). Kehadiran Allah dalam ciptaan menjadikan setiap ciptaan memiliki nilai intrinsik (memiliki nilai pada dirinya). Dalam diri Kristus Allah hadir untuk menebus segala sesuatu. ${ }^{15}$

Karya penebusan ini memperjelas bahwa, setiap suku, ras, setiap jenis hewan dan tumbuhan dan segala ciptaan tidak boleh punah, tetapi harus lestari bahkan manusia akan bertemu dan mengenal jenis dan corak baru ciptaan yang belum dikenal sebelumnya. Allah Pencipta segala sesuatu, dengan setia hadir di bumi untuk menebus segala ciptaan-Nya. ${ }^{16}$

13 Pedapat St. Bonaventura dalam Ilia Delio, Revisting the Franciscan Doctrine..., hlm. 17-18.

${ }^{14}$ Ilia Delio, Doa Fransiskan..., hlm. 164.

15 Bernadeta Harini Tri Prasasti (ed.), Lingkungan Hidup, Jakarta, Departemen Dokumentasi dan Penerangan Konferensi Waligereja Indonesia, 2014, hlm. 174; Larry Rasmussen, Komunitas Bumi..., hlm. 509-510.

${ }_{16}$ Jay B. McDaniel, With Roots and Wings, Chrisianity in an Age of Ecology and Dialogue, Orbis Books, New York, 1995, hlm. 112. 


\section{Allah Tidak Meninggalkan Dunia}

Keadaan nyata dunia yang rusak, dan kelakuan nyata manusia yang jahat di bumi, bukan menyatakan bahwa Allah mulai bosan dengan ciptaan-Nya, justru sebaliknya, keadaan demikian makin menguatkan keyakinan orang beriman bahwa Allah terlibat hadir untuk memperbarui bumi ciptaan-Nya. Menurut Martin Luther, Allah jelas hadir dalam kelemahan dan kehancuran, dalam kegelapan, kegagalan, kesedihan, dan keputusasaan. Allah hadir di sana dalam cara khusus untuk menyelamatkan. Allah hadir dalam kasih yang menderita. Allah hadir dalam keterlibatan dan kesakitan, bukan hanya di keindahan dan kesehatan. Allah ikut menderita mengalami derita alam. ${ }^{17}$

Dengan peristiwa salib Allah hadir dalam kerusakan, dengan kehadiran dan keterlibatan itu Dia menyembuhkan. Allah rela menderita supaya manusia menjadi kuat dan rela memikul tanggung jawab duniawi, agar manusia bukan lari dari dunia, atau meninggalkannya. Orang yang menghindari bumi tidak menemukan Allah yang sudah memilih bumi menjadi tempat tinggal-Nya dengan berinkarnasi. Orang yang mengasihi Allah tentu mengasihi Allah di bumi, dan yang mengasihi bumi tentu mengasihi Allah pencipta dan pemilik bumi. Barang siapa mengasihi Kerajaan Allah, mengasihi Kerajaan tersebut sepenuhnya sebagaimana Kerajaan Allah di bumi. ${ }^{18}$

Allah tidak meninggalkan dunia. Dia tidak melupakan manusia karena Dia telah hadir dan menyatuan diri-Nya secara definitif dengan bumi. Allah datang dan hadir tetap di bumi tempat yang benar untuk manusia dan ciptaan lain. Allah bukan saja mengaruniakan bumi kepada manusia, tetapi juga memampukan manusia untuk mengolahnya dengan mematuhi tata bumi agar sesuai dengan tujuan awal dan sekaligus tujuan akhir penciptaan. Manusia wajib menghormati struktur kodrati dan moral yang telah diterimanya dari Allah. Tanpa jatuh pada antroposentrisme, peran dan kemampuan unik manusia berupa pengetahuan, kehendak, kebebasan, dan tanggung jawab yang dianugerahkan Allah Pencipta, sangat penting dalam memelihara bumi dan isinya serta keseimbangan dan kelestariannya. ${ }^{19}$ hlm. 498 .

17 Pendapat Martin Luther dalam Larry Rasmussen, Komunitas Bumi...,

${ }^{18}$ Larry Rasmussen, Komunitas Bumi..., hlm. 531-532.

19 Paus Fransiskus, Ensiklik Laudato Si'..., no. 115; Ilia Delio, Doa Fransiskan..., hlm. 192. 


\section{Bumi dan Langit yang Baru}

Yesus berkata, "Lihatlah, Aku menjadikan segala sesuatu baru" (Wahyu 21, 5). "Kehidupan kekal akan menjadi sebuah pengalaman bersama yang mengagumkan, di mana setiap makhluk berubah rupa dengan kegemerlapan." 20 Sistem alam akan tetap baru, dan manusia akan menemukan hal baru di masa depan, karena belum (tidak) semua bisa ditangkap manusia dari dulu sampai sekarang. Alam semesta memiliki sitem yang baik, sehingga bumi menjadi rumah bagi makhluk yang berdiam di dalamnya. Dengan kekayaan unsur (tanah, hutan, samudera, atmosfir, dan lainnya) dan variasi sifat ciptaan yang ada, bumi pada dasarnya dapat menyembuhkan dirinya sendiri.

Setiap orang baik secara pribadi maupun kelompok dipanggil pada suatu pengharapan untuk hidup di bumi yang baru dan langit yang baru. Gambaran bumi dan langit yang baru merupakan suasana di mana makhluk manusiawi, makhluk hewani, makhluk tumbuhan serta unsur alam lain, saling harmonis dan saling melindungi secara lestari. Perwujudan keadaan demikian bukan hanya prakarsa dari Tuhan, tetapi juga perlu tindakan proaktif dari manusia.

Yesus bukan saja menggunakan unsur-unsur alam dalam perumpamaan-Nya dan menafsir alam dengan cara ilahi, tetapi Ia juga berkuasa atasnya (Mat 14, 22-23). Tuhan menempatkan alam dalam rencana penebusan-Nya. Ia meminta para murid-Nya untuk mencermati beberapa tanda-tanda alam, mencermati musim dan dengan demikian yakin bahwa Allah Yang Maha baik setia memelihara ciptaan-Nya. Pemeliharaan alam ini dipercayakan pada manusia dengan bijaksana dan kasih. ${ }^{21}$

\section{Bertindak Lokal}

Menurut Steven Covey ada dua penciptaan, yaitu penciptaan ide dan tindakan. Ciptaan pertama yang merupakan keyakinan yang benar dan ditopang hati nurani yang tajam yang dimiliki manusia, membantu

20 Paus Fransiskus, Ensiklik Laudato Si'..., no. 243.

${ }^{21}$ Bernadeta Harini Tri Prasasti (ed.), Lingkungan Hidup..., hlm. 90, 109; Paus Fransiskus, Ensiklik Laudato Si'..., no. 205, 254. 
ciptaan kedua, yaitu manusia bertindak baik dan bijaksana.22 Ciptaan pertama,

“Didasarkan pada imajinasi - kemampuan untuk melihat potensi, untuk menciptakan dengan pikiran kita apa yang tidak dapat kita lihat sekarang ini dengan mata kita; dan suara hati kemampuan untuk mendeteksi keunikan diri kita sendiri dan pedoman, moral, dan etis pribadi yang kita ingin memenuhinya dengan gembira. Kebiasaan ini merupakan kontak yang dalam dengan paradigma dasar kita dan nilai serta visi tentang dapat menjadi apakah kita nantinya." 23

Citptaan kedua adalah "pemenuhan, aktualisasi... Ia merupakan pelaksanaan hari demi hari, saat demi saat." 24

\section{Perumusan Ide (Penciptaan Pertama - Visi)}

Allah berkata, "Let us make man in our imagine, after our likeness; and let them have dominion over the fish of the sea, and over the birds of the air, and over the cattle, and over all the earth and over every creeping thing that creeps upon the earth" (Kej. 1, 26). Pernah diinterpretasi bahwa Kejadian 1, 26 ini dan Kej 1,28 sebagai satu alasan bahwa manusia boleh mengeksploitasi alam. "On the contrary, the Hebrew Bible and Jewish interpreters prohibit such exploitation. Judaism goes much further and insists that humans have an obligation not only to conserve the world of nature but to enhance it because the man is the 'co-partner of God in the work of creation'." 25

Sebagaimana Allah mencipta manusia menurut imagine-Nya, pergerakan mengatasi masalah lingkungan sebaiknya dengan imajinasi iman yang tepat. Perhatian pertama diarahkan pada pemulihan dimensi spiritual atas relasi terhadap ciptaan, dengan menemukan kembali pesan Allah yang sejak awal mempercayakan ciptaan kepada manusia

22 Stephen Covey, The 7 Habits of Highly Efective People (7 Kebiasaan Manusia yang Sangat Efektif), Jakarta, Binarupa Aksara, 1997, hlm. 89.

${ }^{23}$ Steven Covey, The 7 Habits..., hlm. 138-139

24 Steven Covey, The 7 Habits..., hlm. 139.

25 Rose, Aubrey Rose, (ed). Judaism and Ecology, New York, Cassel, 1992, hlm. 136. 
(Kej 2, 15). "Ekologi internal" memajukan "ekologi eksternal".26 Orang Kristen (tanpa tergelincir pada antroposentrisme) hendaknya tahu bahwa tugas mereka merawat ciptaan dan menghormati Sang Pencipta yang hadir dalam dirinya, merupakan tanggung jawab integral sebagai orang beriman..$^{27}$

Gerakan ekologis tidak bertentangan dengan inovasi teknologi yang meningkatkan kualitas hidup. Agar terjadi kemajuan secara menyeluruh, orang beriman harus bijakasana menentukan batas kemajuan dan pengembangan perekonomian, agar penggunaan sumber daya alam bisa berkelanjutan dengan mempertimbangkan sistem alam. Dibutuhkan keterbukaan pada aneka kemungkinan berbeda, keterbukaan pada kreativitas manusia dan cita-cita kemajuan, tetapi mengarahkan energi dan kemajuan ke jalur-jalur baru berdimensi ekologis. ${ }^{28}$

Pendidikan berperan penting dalam menyadarkan dan mempromosikan "kewarganegaraan ekologis dan persaudaraan kosmis". Pendidikan hendaknya tidak sebatas memberi informasi tetapi juga mengembangkan kebiasaan-kebiasaan baik pengembang tanggung jawab ekologis sekaligus pendorong kebiasaan baik dan perilaku yang memiliki dampak langsung dan signifikan untuk pelestarian lingkungan. ${ }^{29}$

Orang yang berimajinasi ilahi dan yang memiliki cinta mendalam akan Allah sadar dan mengerti bahwa Kristus sebagai pusat dari semesta. Kristus adalah "Sabda Allah yang melalui-Nya segala sesuatu dicipta, Sabda yang mengambil kodrat manusiawi kita yang sekarang bangkit dan dimuliakan." 30

\section{Bertindak Bersama demi Bersama (Penciptaan Kedua - Misi)}

Jiwa bangkit hendaknya dimiliki secara bersama agar bumi ini menjadi rumah damai bersama. “Tuntutan-tuntutan pekerjaan ini begitu besar sehingga tidak dapat diselesaikan oleh inisiatif individu, atau oleh

\footnotetext{
${ }^{26}$ Bernadeta Harini Tri Prasasti (ed.), Lingkungan Hidup..., hlm. 94.

27 Paus Fransiskus. Ensiklik Laudato Si'..., no. 64.

28 Paus Fransiskus. Ensiklik Laudato Si'..., no. 187, 190, 191, 193.

${ }^{29}$ Paus Fransiskus, Ensiklik Laudato Si'..., no. 211, 254.

30 Ilia Delio, Doa Fransiskan..., hlm. 192.
} 
sekumpulan pribadi-pribadi yang dididik secara individualistis. Diperlukan gabungan kekuatan dan kesatuan usaha (komunal)." 31

Ada beberapa tindakan ${ }^{32}$ bersama secara konkret yang bisa dipromosikan dan dibiasakan, agar tindakan berefek ekologis secara signifikan. Kebersamaan internasional menyepakati kebijakan yang mengikat untuk setiap negara. Kebersamaan nasional membuat hukum yang mengikat semua warga untuk memelihara lingkungan hidup. Kebersamaan lokal memilih prioritas yang cocok di lokalnya dalam bingkai bumi bersama. Menarik tindakan konkret yang dipromosikan di Keuskupan Agung Jakarta (KAJ). Masyarakat atau umat KAJ diajak untuk memilah sampah, hal ini dipilih karena masalah sampah di kota besar cukup menonjol dan mudah dilakukan oleh siapa saja yang sudah memiliki kesadaran ekologis. Sampah organik diolah menjadi kompos yang bisa digunakan untuk menyuburkan pohon-pohon yang ditanam di tempat yang cocok. Masalah banjir juga diatasi dengan penataan air tanah dengan resapan air dengan membuat biopori dan sejenis bak tanah. ${ }^{33}$

Tindakan bijak juga bisa dengan menggunakan kekayaan alam secukupnya, misalnya memasak makanan secukupnya, memperlakukan

${ }^{31}$ Paus Fransiskus, Ensiklik Laudato Si'..., no. 219.

32 Paus Benediktus XVI dalam pesan hari perdamaian sedunia ke - 43 menyebut beberapa tindakan yang mungkin dilakukan untuk melindungi ciptaan, antara lain: masyarakat internasional dan pemerintah nasional harus melindungi lingkungan dengan tata hukum dan kegiatan ekonomi yang tepat sehingga generasi sekarang dan mendatang hidup sejahtera, pengembangan penelitian tentang lingkungan dan penerapan bentuk energi yang lebih ramah lingkungan misalnya energi sinar matahari, pengembangan pertanian, pengelolaan hutan, pendidikan kesadaran lingkungan dengan perhatian pada kesejahteraan bersama, lihat Bernadeta Harini Tri Prasasti (ed), Lingkungan Hidup, Jakarta, Departemen Dokumentasi dan Penerangan Konferensi Waligereja Indonesia, 2014, hlm. 169 - 175; Para Uskup Indonesia dalam Nota Pastoral KWI, Keterlibatan Gereja dalam Melestarikan Keutuhan Ciptaan, 2013, no. 19-22, mempromosikan pastoral ekologi atau ekopastoral yang menyeluruh dan berkesinambungan. Secara khusus diberi perhatian agar saudara-saudari yang berperan dalam mengambil keputusan meninjau ulang bila perlu menghentikan pengembangan yang mencemari lingkungan hidup, memperhatikan kawasan hijau dan resapan air, pendidikan kesadaran ekologis.

33 Widyahadi Seputra, dkk. (ed.), Kajian Lingkungan Hidup..., hlm. 140, 145. 
makhluk hidup lain dengan baik, dll. ${ }^{34}$ Di samping itu penggunaan arif benda-benda yang ada dengan prinsip $3 \mathrm{R}$ yaitu, reuse (memakai ulang benda yang masih bisa digunakan, misalnya kantong plastik), reduse (mengurangi pemakaian benda, misalnya mengurangi pemakaian plastik dan pemakaian kertas), recycle (mengolah/mendaur ulang benda yang sudah selesai pakai, misalnya baskom pecah yang terbuat dari plastik didaur ulang menjadi baskom plastik yang baru). Sikap Paska direalisasikan dalam usaha penanaman bervariasi jenis tanaman produktif untuk menghindari tanaman sejenis di lahan luas. Sikap Paska tampak juga dalam usaha membatasi penggunaan pupuk kimia dan pestisida agar tanah tidak rusak dan hewan-hewan kecil tidak punah. Orang beriman dipanggil untuk menjaga hutan agar tersedia air bersih dan udara bersih. Tindakan bersama dan personal secara konkret untuk memelihara lingkungan adalah tanggung jawab setiap orang beriman sehingga bumi ini menjadi rumah bersama untuk mengalami penebusan Allah dalam diri Kristus yang bangkit.

\section{Penutup}

Kristus yang bangkit tinggal di bumi bersama orang beriman, agar kebangkitan-Nya menjadi pengalaman baru untuk orang beriman dalam hidup bersama dengan semua ciptaan yang berhayat dan tidak berhayat serta yang kelihatan dan tak kelihatan. Bumi sebagai rumah bersama yang berisi kekayaan unsur dan variasi sifat, bisa mengharmoniskan dirinya, tetapi dibutuhkan peran manusia yang memiliki kehendak baik untuk mengendalikan gerakan harmonisasi dan kedamaian lestari ke arah yang dikehendaki Sang Pencipta. Orang beriman dipanggil untuk bertindak konkret secara personal dan bersama di lokasi masing-masing.

Tindakan praktis orang beriman berdaya rohani kalau diresapi oleh Doa Kebangkitan, yang diucapkan bersama semua ciptaan, "Putra Allah, Yesus, segala sesuatu diciptakan melalui Engkau. Engkau dibentuk dalam rahim Maria, Engkau telah menjadi bagian bumi ini, dan Engkau telah melihat dunia dengan mata manusia. Sekarang ini Engkau hidup dalam setiap makhluk dengan kemuliaan kebangkitanMu." 35

34 Paus Fransiskus, Ensiklik Laudato Si'..., no. 211.

${ }^{35}$ Doa Kebangkitan ini sebagian dari Doa untuk Bumi Kita dalam Paus Fransiskus, Ensiklik Laudato Si'..., no. 246. 


\section{DAFTAR PUSTAKA}

Covey, Stephen. The 7 Habits of Highly Efective People (7 Kebiasaan Manusia yang Sangat Efektif), Jakarta, Binarupa Aksara, 1997.

Delio, Ilia. Doa Fransiskan, Medan, Bina Media Perintis, 2018.

- Revisting the Franciscan Doctrine of Christ, cdn.theologicalstudies.net

Durrwell, F.X. "Resurrection of Christ" dalam New Chatolic Encyclopedia, Volume XII, Washinton, The Catholic University of America 1967

Léon-Dufour, Xavier. Resurrection and the Message of Easter, New York, Geoffrey Chapman 1974.

McDaniel, Jay B. With Roots and Wings, Christianity in an Age of Ecology and Dialogue, Orbis Books, New York, 1995.

Paus Fransiskus. Ensiklik Laudato Si', tentang Perawatan Rumah Kita Bersama, Jakarta, Obor, 2015.

Prasasti, Bernadeta Harini Tri (ed.). Lingkungan Hidup, Jakarta, Departemen Dokumentasi dan Penerangan Konferensi Waligereja Indonesia, 2014.

Rasmussen, Larry. Komunitas Bumi, Etika Bumi, Merawat Bumi demi Kehidupan yang Berkelanjutan bagi Segenap Ciptaan, Jakarta, BPK Gunung Mulia, 2010.

Rose, Aubrey (ed). Judaism and Ecology, New York, Cassel, 1992.

Seputra, Widyahadi dkk. (ed). Kajian Lingkungan Hidup, Tinjauan dari Perspektif Pastoral Sosial, Jakarta, Sekretariat Komisi PSE/APP KAJ dan Komisi PSE-KWI, 2010. 